\title{
Common Ground: Melodramas of 9/11
}

On September 11, 2001, the US joined the rest of the world in a common history marked by death, suffering, and mass violence — or so the dominant narrative would have it. "History has called America and our allies to action, and it is both our responsibility and our privilege to fight freedom's fight," said President Bush in his 2002 State of the Union address. Similarly, the 2002 National Security Strategy talks about the "new world we [the US] have entered." Indeed, the official historical narrative of $9 / 11$, the one promoted by the Bush administration and mainstream media insists precisely on the status of $9 / 11$ as a "watershed moment." The assumption according to which the US was excluded from history up to the moment of violent foreign intervention on domestic soil forms the backdrop for many fictional accounts of 9/11. Echoing the logic of the National Security Strategy, John Barth refers to the WTC attacks as "The End Of The World As We (Americans) Knew It" (1). In Ken Kalfus' A Disorder Peculiar to the Country, a US doctor originally from Afghanistan speaks his mind to a survivor of the WTC attacks: "Now you know what it's like to live in history" (58, my emphsis).

In this hegemonic narrative, 9/11 marks the moment when the main protagonist, the US nation, breaks up with a past that is equated with an almost childlike innocence and is made to, somewhat reluctantly, take action and thus "enter history." The fact that, in this case, entering history implied taking military action in the geographically distant territories of Afghanistan and Iraq shifts the strictly national framing of the event. In other words, although

1 It has been noted that the narrativization of $9 / 11$ in terms of a radical break or a historical turning point contributed to its political instrumentalization on the part of the US government. In Mary Dudziak's words, any analytical approach to the event has to account for "the political consequences of the construction of September 11 as a moment of change." According to her, "Since September 11, the idea of change has been deployed to justify departure from past practices, from a new secrecy in detention and deportation of noncitizens to the preemptive use of American military power." (Dudziak 8) 
encoded primarily in terms of national tragedy, the event was used as a basis for the claim to the right of the US to "become" an agent of world history. In that sense, 9/11, a moment that expanded into the infinite "now" of the "global war on terror," functioned also as a point of spatial, imperialist expansion. In Jonathan Safran Foer's novel that I focus on here, the events that interrupt the history of an American family — the bombing of Dresden, 9/11—function also as points of symbolic integration of the affected subjects into the larger history of US presence in other parts of the world (Europe, the Middle East).

Despite the unquestionable global impact of the attacks, contemporary US fiction has remained entrenched in the most common mode of cultural encoding of the $9 / 11$ event: that of family drama. Here, the event figures primarily as a turning point in the private lives of the protagonists. Novels such as Julia Glass's The Whole World Over (2006), Wendy Wasserstein Elements of Style (2006), John Updike's Terrorist (2006), or Claire Messud's The Emperor's Children all deal primarily with family relations, putting special emphasis on children or adolescents. More (Messud) or less (Glass) ironically or critically distanced from their familial subject matter, these narratives often inscribe the WTC attacks as a decisive moment in the process of a character's personal growth. In the case of children characters, who literally pervade the pages of the popular post-9/11 fictions, this moment marks a break in the protagonist's development towards full subjectivity, a desire for autonomy realized through a symbolic rite of passage. That family should function as the representative site of national politics is certainly not a peculiarity of the post-9/11 moment. Lauren Berlant has convincingly shown how, in the closing decades of the twentieth century, children came into the focus of US public discourse, achieving a status of "national supericonicity." As Berlant puts it, "the fetal/infantile person is a stand-in for a complicated and contradictory set of anxieties and desires about national identity" (6). Taking on Berlant's cue about the centrality 
of the intimate sphere for the constitution of national politics, I want to emphasize how the basic narrative logic of many $9 / 11$ fictions corresponds to the hegemonic emplotment of the event by representing it as a critical moment in which personal, familial, and national history take a turn towards self-realization. Through the correspondence of these histories, the individual (often traumatized) body and the national polity emerge as naturally contiguous. Moreover, the popular fictions of $9 / 11$ more often than not rewrite the traumatic event in terms of the emergence of a "new" subject.

Claire Messud's The Emperor's Children is exemplary in this respect. In one of the several story-lines of the novel, Bootie, a teenager trying to free himself from the constraints of the family circle in order to become an autonomous individual, happens to escape death in the Twin Towers by sheer luck, while everyone thinks he has died (similar to LaBute's Ben). On September 11, 2001, the collapsing towers for Bootie coincide with the moment of his illumination: he realizes that the man he had idolized (the "Emperor" from the novel's title) is just one of many "false idols," and describes the sight as "the Tower of Babel tumbling" (392). Since for him the catastrophe simply means that "you could . . change the world," (395) Bootie changes his name to Ulrich New and decides to start a new life. Messud's irony is certainly always there to signal to the reader that this new life is far from the idealized expectations of personal fulfillment, but the figurative power of the event-its openness to inscription into various personal narratives - nevertheless remains the structuring force of the novel. Other characters, too, see the catastrophe primarily as an event that figures primarily in their own lives, be it as a metaphor for the end of a love relationship (Danielle), or the end of a business career (Ludovic).

Typically, the traumatic event is inscribed in these popular fictions as a crucial moment in an often narcissistic and melodramatic personal or familial story, and narrated 
primarily in relation to the dominant subject-position and its imagined telos. Before moving to the novel that I find especially interesting in this context, I would like to make a few general observations about the implications of the common assimilation of $9 / 11$ as a backdrop for family drama. On the one hand, this rhetorical move is in line with the continuing tendency in the post-9/11 United States to reduce the event to familiar contexts. Family here functions as a sometimes troubled, but always desirable and representative unit, of US society, and it is certainly not insignificant that most families in these fictions live comfortable upper-middle-class lives. But, as Judith Butler warned after September 11, the price to be paid for a process of grieving based on familiarity is the exclusion of various "others" from humanity (38). The "norms of recognition"- the complex set of cultural and social practices that establish the conditions for the recognizability of various othersbecome in this context a preeminent ethico-political problem (cf. Butler 43). The 9/11 family fictions set affective limits to the "norms of recognition" by containing them within the boundaries of the most familiar, literally keeping things in the family. Melodrama here functions as the central genre that works to translate the political into the personal. It is worth noting that such translation is also a central rhetorical strategy of the dominant ideology of neoliberalism, which always displaces the site of agency onto the individual and rewrites systemic issues in psychological and private terms ${ }^{2}$. On the other hand, these narratives repeat and reinforce the rhetoric of break that dominates the $9 / 11$ discourse. This break is always situated in a narrative of individual development, which is, in the novelistic tradition, commonly couched in some variant of the Bildungsroman genre. It is in the novel of formation, which provides one of the basic generic frameworks for the aforementioned novels, that we can start to detect the same underlying evolutionist historical consciousness

2 Berlant stresses the process of fostering "a nationalist politics of intimacy" during the Reaganite neoliberal revolution, where "normal intimacy" defined in sexual, racial, and economic terms came to set the limits of the proper practice of US citizenship (7). 
that is also at work in the writing of national history. This developmental narrative, which backs both the $9 / 11$ personal/family dramas and the hegemonic narrative of the US nation, makes the history of the family and the nation appear not only comparable, but compatible.

A nation's linear progression through historical time is an idea Benedict Anderson has related to the emergence of modern nationalism. An ancient history of a nation is always imagined in retrospective, as a justification for contemporary claims to sovereignty. The "historical linearity" of national histories is thus modeled, Prasenjit Duara argues, on "an evolutionism in which the species is replaced by the nation, whether constituted by race, language, or culture" (26). Duara adds to this observation by pointing to a more general underlying narrative logic at work: "Even multicultural histories reproduce essentially the same evolutionary narratives, identifying a subject of history that gradually gathers the selfconsciousness that will enable it — be it gays or an ethnic group — to claim its rights." (26) Writing about the Bildungsroman genre in a different, although not unrelated context, Joseph Slaughter summarizes the basic qualities of the genre: fundamentally driven by a "socialpreservationist" impulse and resting on a "progressive temporality," the novel of formation enacts a "process of subjectivation" usually described in terms of "socialization, apprenticeship, assimilation, acculturation, and accomodation." Slaughter reminds us that the social work of this "reconciliatory genre" is historically connected to the emergence of modern nation-states: "The genre provides the normative literary technology by which social outsiders narrate affirmative claims for inclusion in the franchise of the nation-state, the story form of incorporation through which the historically marginalized individual is capacitated as a citizen-subject ..." (1411) This incorporative logic is in line with Duara's description of the evolutionist narrative, where "gays" and "ethnic groups" represent the "marginalized individuals" in the process of social integration. For Slaughter, "Bildungsroman" is not "the 
name of some typologically consistent literary artifact ..., but ... the name of a function, the generic label that good reformists repeatedly give to texts that perform a certain kind of incorporative literary social work." (1411) Slaughter also points to a "logical and temporal twisting of the developmental structure" typical of the genre, which he terms an "impossible tautological-teleological developmental complex:" the formation of the protagonist depends on "the narrative process through which the Bildungsheld retroactively becomes responsible for the plot of personality development and so for fate and state" (1412).

Here I would like to part with Slaughter, who goes on to explore the connections between this paradoxical structure of the Bildungsroman and the discourse of human rights. What I want to stress is the overlapping of the basic structure of the novel of formation and a nation's history - the same "impossible" structure is at work in the writing of national history as described above by Duara: as with the hero of the Bildungsroman, "[h]ere a contemporary nation that 'causes' the narrative posits itself as an effect of it" (Duara 29). In most general terms, these evolutionary narratives with paradoxical temporal structure act as justifications for an already existing subject-position by imagining an organic, or natural, foundation for its historical existence: the citizen thus emerges through the socialization of the uncivilized, "natural" social outcast, as the nation-state is formed through the narrative incorporation of a pre-existing, "organic" nation. I focus on this structural correspondence between Bildungsroman and linear national history in my reading of Foer's Extremely Loud and Incredibly Close, which I understand as a post-traumatic novel of formation that enacts the process of the nation's restorative mourning after 9/11. Inscribed in such a developmental narrative, the trauma of $9 / 11$ becomes a point of suture between the personal and the communal, between the body in pain and the body politic. 
Foer's 2005 book explicitly treats $9 / 11$ in terms of trauma. A novel about a disintegrated subject, it performs the work of social reintegration through a process of posttraumatic mourning. In psychoanalytic terms, it can be read as a story of post-traumatic acting out and working through. The process of social healing and reestablishing of affective ties is in this text embedded in the "imaginative mode" of melodrama and, being in large part a story of coming-of-age, in the historical genre of the novel of formation. Foer's text uses many narrative devices common to $9 / 11$ fiction in general — the growth of a child hero, the focus on family relations (the disintegration and reconstruction of the family), historical references to the Second World War and the Holocaust - all wrapped up in a narrative clearly leaning towards the "mode of excess" that Peter Brooks recognizes as melodramatic. In terms of narrative structure, Foer's text incorporates a variety of visual material: in particular, he makes an apparently controversial move in including the often censored photographs of people falling from the WTC on September 11, 2001. ${ }^{3}$ In a short 2005 interview, Foer comments on the appropriateness of art about 9/11. In a move that is typical of other authors of 9/11 fiction, Foer starts by drawing a sharp distinction, if not an outright opposition, between the media and artistic representations of the event:

It troubles me when people ask if it's too early to make art pertaining to September 11. No one asked, in the moments after the attacks, if it was too early for Tom Brokaw to report it. Do we trust Tom Brokaw more than we trust, say, Philip Roth? His wisdom, his morality, his vision? I don't. I appreciate that Tom Brokaw and Philip Roth do entirely different things, both necessary. I wouldn't want Roth giving me my information about what happened on a given day in

3 That the novel's melodramatic inclination should be overlooked can have to do with the fact that Foer is an author with an already established "high" literary status thanks to his very successful first novel, Everything is Illuminated. Using canonical post-modernist pastiche techniques, and, unlike a lot of sentimental prose that employed the motif of the WTC attacks, less bound by rules of genre, Foer's popularity is also due to the fact that his novel is more easily read than, say, Paul West's philosophical-essayistic The Immensity of the Here and Now or the anti-melodramatic Falling Man by Don DeLillo. 
Baghdad, and I wouldn't want Brokaw giving me my information about what it felt like. Journalists traffic in biography. Artists traffic in empathy. We need both. (Hudson)

Information and feeling, biography and empathy — these are, for Foer, the clearly distinct grounds on which the division of labor between media and literature can be carried out. Having in mind the large number of critical studies of the US media coverage of 9/11 and the ensuing wars, and the common contention that their work in times of war has been based on playing up an "emotionalized patriotism" (Jeffords \& Rabinovitz 23), such clear demarcation between the spheres of "fact" and "feeling" become hardly sustainable. In my view, although distancing his work from the media, Foer's novel employs some basic representational strategies that are considered to characterize the US media, in particular after 9/11.

Generally, critics recognize melodrama as the "impermeable deep structure" of US corporate media reporting (Solomon 1590). Alisa Solomon calls it “America's national dramaturgy," (ibid.) and traces the roots of its hegemony in the US media space to the "first imperial adventures in Cuba in the name of rescuing the native women from the Spaniards who would defile them" (1591). Analyzing the media representations of the first Gulf War, Robyn Wiegman also stresses the role of melodrama in national homogenization in times of war: "it is through the melodramatic plottings of family trauma, separation and loss that a reluctant citizenry ultimately distinguished between the war and its soldiery in order to align itself overwhelmingly 'in support of the troops.'” (173) Relying on Peter Brooks' classical study, Wiegman argues that melodrama - a genre that functions to secure "essential and uncontradictory truths," and "a stable moral order" (181)_-“achieves its reassuring effect not only by collapsing the public into the private but by negotiating that collapse through the figuration of the masculine and its crisis of socio-symbolic location" (181-182). The 
melodramatic is thus a central cultural discourse. Actually, it could be argued that melodramatic narrative provides the implicit framing for all "news" or "information" that reaches various US constituencies. This is especially so, Wiegman's and Solomon's essays suggest, where the news concerns catastrophic and violent occurrences:

Experience emerges as epistemologically central, relying for its truth on the emotional texture of lived extremes. For this reason, melodrama privileges the psychic contexts of suffering, fear and the tragedy of the unforseen. A genre critics have often traced to the social convultions of the French Revolution, melodrama encodes an implicitly bourgeois social organization, dependent on interiority and individualization. (178)

The fundamental social work of melodrama thus consists in the translation of social and political issues into private and individual terms. It is my contention that melodrama is the imaginative mode containing both most of the media coverage and a large number of fictional accounts of 9/11, including, despite the author's proclamations, Extremely Loud and Incredibly Close.

Foer's novel is the story of Oskar Schell, a nine-year-old boy who lost his father in the 9/11 attacks on the World Trade Center. Traumatized by the experience, Oskar hides the tape with his Dad's last phone calls in a closet. After finding a key in an envelope with the name Black written on it, Oskar presumes that it belonged to his father and embarks on a quest for "Black," hoping to learn some mysterious truth about his dead father. Apart from this central first-person narrative, there are two more: one consisting of the unsent letters that Oskar's grandfather Thomas writes to his son, Oskar's father (also called Thomas), and the other consisting of the letters Oskar's paternal grandmother writes to Oskar. (Oskar also writes letters, to famous people.) Each of these series of mostly failed communications 
revolves around loss: the grandfather's letters tell the story of his life in Germany, and the loss of his first love in the firebombing of Dresden. After fleeing to the United States, he marries the dead woman's sister, Oskar's grandmother. Unable to cope with the traumatic memory of his lost love, he leaves the sister after she gets pregnant, and thus never meets his son, to whom the letters that we learn the story from are addressed to. Eventually, he returns, sees the 9/11 terrorist attacks on TV, returns to his wife, and keeps his presence hidden from Oskar. The grandmother's letters deal with the loss of her husband, who leaves her, and her son, who dies on 9/11. There are many other stories of loss in the novel, which we learn about during Oskar's search for the owner of the mysterious key. This short plot outline clearly demonstrates that Extremely Loud and Incredibly Close is first of all a family story encompassing several generations of Schells. Family history is reduced here to a history of trauma and loss. The central allegory for the novel's conceptualization of history and subjectivity is to be found in the story of the sixth borough of New York City (222). In this story, which Oskar hears from his father, New York has inexplicably lost its sixth borough, of which only one part has been saved, Central Park. Now, the lost sixth borough is wandering around the world with a hole where Central Park used to be. Significantly then, an essential, iconic part of New York points to a loss, while the trace of that loss is constitutive of the city's identity. Trying to cope with his personal traumatic loss, Oskar hides the phone with the recording of his father's last phone call: that secret "was a hole in the middle of me," (71) says Oskar, echoing the allegory of the sixth borough. Trauma here functions as both a disrupting and formative moment that points to an identifying, central part (as with "Central Park") of the subject's being.

Moreover, Oskar constantly reenacts his trauma by listening to the tape of his Dad's last phone call on 9/11. Unable to mourn and let go of the lost object of his affective 
attachment, Oskar is a melancholic: his acts of self-injury reflect the "impoverishment of the ego" and "self-abasement" that Freud finds to be typical for melancholia, a condition characterized by an "overcoming of the drive [...] which compels everything that lives to cling to life" (Freud 2005: 205-206). At the same time, Oskar is, in Freud's terms, "taking satisfaction from self-exposure" (Freud 2005: 207) and is unable to stop talking, writing letters, or asking questions. Oskar's defiance of the reality principle is ultimately obvious in his desire to dig up his father's grave. This defiance is by definition melodramatic. According to Peter Brooks, melodrama represents a "victory over repression" (41): "The melodramatic utterance breaks through everything that constitutes the 'reality principle,' all its cesorships, accomodations, tonings-down." It provides the possibility to say what is in "real life" unsayable and thus "achieve the full expression of psychological condition and moral feeling in the most transparent, unmodified, infantile form" (41). As I have argued above, post-9/11 fiction's focus on children characters is a mark of such melodramatic infantilization. ${ }^{4}$

In Foer's melodrama of 9/11, the trauma is worked through to the effect of renewing affective ties inside an already existing community. The family that is the protagonist of the novel provides the reader with a model for a cathartic exercise of empathy. Thus, Extremely Loud and Incredibly Close participates in the culture of national

4 There is a potential methodological complication here that needs to be addressed. Brooks warns that psychoanalysis is "a systematic realization of the melodramatic aesthetic." (200) Is it then a tautology to read melodrama through a psychoanalytic lens? Doesn't that, following Brooks, ultimately boil down to a reading of melodrama through melodrama? Brooks stresses the common imaginative background behind both representational modes: "Melodrama and psychoanalysis represent the ambitious, Promethean sense-making systems which man has elaborated to recuperate meanings in the world." (202) This recuperation of meaning is for Brooks linked to the fact that melodrama historically emerges after the French Revolution, "the moment that symbolically, and really, marks the final liquidation of the traditional Sacred and its representative institutions (Church and Monarch), the shattering of the myth of Christendom, the dissolution of an organic and hierarchically cohesive society ..." (15) These pronouncements, which relate the melodramatic mode to the "loss" of the Sacred and the "dissolution" of organic community, suggest that melodrama is a possible reaction to a historical trauma that destroys the presumed foundations of communal experience. It would appear then that the methodological tautology can be productive: a psychoanalytic term, trauma, can help us understand the social work of melodrama. If we agree that "[m]elodrama starts from and expresses the anxiety brought by a frightening new world in which the traditional patterns of moral order no longer provide the necessary social glue," (Brooks 20) then melodrama can be read as a conventional cultural mode of post-traumatic restoration. 
commemoration of $9 / 11$ by providing a narrative of successful mourning through melodramatic closure. However, the social ties restored by the process of mourning are in the novel firmly anchored in the body, and the historical continuity of the affective community is consequently predicated on the transmission of genetic material. Such physical or organic grounding of the social unit in mourning — the family and the nation — sets certain limits to the affective attachments they solicit, reducing them to familial and familiar contexts.

Different forms of traumatic loss both sever and reestablish family ties in the novel. This is true even literally: after a long silence, the absent grandfather sends a letter to his wife on the day of their son's death, September 11, 2001 (233). The same event, and the search for the origin of the key that ensues, is also what finally leads Oskar to meet and get to know his grandfather. Apart from the family, during his search Oskar meets other New Yorkers, thus establishing himself as a member of the national community, of which the random sample of US citizens, united in their particular grieving, is representative. The trauma of 9/11 then, paradoxically, at once destroys the normalcy of family life and restores the interrupted continuity of family history through providing an intergenerational link between Oskar and his grandfather. Through the experience of trauma, Oskar, the central consciousness of the novel, is inscribed in the overlapping histories of the Schell family and the US nation.

Crucial for the continuity of these histories is an Oedipal line of repetitive identifications rehearsed at several points in the novel. The crisis of the masculine, which according to Wiegman is typically melodramatic, takes place on 9/11 when Oskar's father dies. Identifying with his dead father, Oskar tries to keep close to his memory through compulsively listening to the hidden tape with his father's last phone call. Here a vicious circle of Oedipal identifications begins, and everyone recognizes as familiar what is already 
part of the family. When the long gone grandfather hears Oskar's voice for the first time, he hears "my own voice, and my father's and grandfather's" (276). The reason the grandfather gives to his son when trying to explain why he left them is "so you [his son] could be you" (277). Eventually, however, his son, Oskar's father, becomes uncannily similar to his father despite this apparent request for autonomy. His melancholic attachment is reinforced, similar to Oskar's obsession with the tape with his father's voice, by his obsessive rereading of the only letter his father sent him (277). This overwhelmingly powerful Oedipal history of the Schells suggests that sons "become themselves" through identification with their lost/absent fathers, and thus establish the continuity of family history. Consequently, the trauma of 9/11 in Extremely Loud and Incredibly Close is represented not simply as a family crisis, but as a crisis of family history: the continuity that Foer's fragmentary narrative reconstructs depends on the potential of trauma to establish affective ties, to integrate, and not only shatter societal common ground. Oskar is finally "healed," and the family unit restored to normal, after several tasks are completed: when he can accept both his father's death and allow his mother to "fall in love again" (324), when he is reconnected to the family history through meeting his grandfather, and when the family history achieves a closed narrative form. It is important to stress that the Schell's historical experience is not only one of trauma, but also one of their successful assimilation, as German Jewish immigrants, into the US body politic. One of the consequences of the grandfather's Second World War traumatic experience-again, as with $9 / 11$, narrated as an intimate story of personal loss - is his relocation to the US: while writing letters about loss, grandfather Thomas also tells the background story of a particular gain, namely, of how the Schells became successful US citizens. Although the story about his Dresden experience is both traumatic and tragic, it implies a story of success: of his immigration and his family's assimilation into US society. In other words, the Schells' family 
history is at the same time an integral part of the history of the United States as a "nation of immigrants."

Foer's novel thus narrates $9 / 11$ as a familial trauma that can be successfully worked through, and as a formative moment in the development of an individual: after a mourning ritual, in which he is reconnected with both his grandfather and, symbolically, his dead father, the socially dysfunctional Oskar is successfully re-assimilated into society. At the same time, the traumatic experience allows Oskar to meet his grandfather and become part of the masculine line of family history. Through a traumatic experience, then, the individual is inscribed in the larger history — of family, of the US nation — that achieves continuity through material embodiment in its "newly" integrated subject. Significantly, the "new" subject that enters history thanks to the trauma of $9 / 11$ is a child, an innocent victim, outside the history that inexplicably happens to him, displacing him only in order to have him safely re-placed. The narrative of the Schell's traumatic family history thus enacts a polyvalent process of integration: familial (through the restoration of the heteronormative family unit, with Ron as an acceptable substitute for Oskar's father), social (Oskar is ultimately able to function as a normal child), and national (the last non-assimilated Schell, the grandfather, apparently returns to a normal life in the US). At the beginning of all of these integrations is the traumatic event, which functions as a point of emergence of an at first disoriented, but ultimately reformed and socially assimilated subject. The reformation is engendered through a process of symbolic working through, as when the grandfather and Oskar are reunited in the dead father's grave, returning to the common ground zero of their traumatic experience.

As I already suggested, the history that needs to be reestablished after the traumatic break of $9 / 11$ is a history that is already founded on family ties: the community that the novel restores is always already there, merely in need of a narrative form that would give 
it continuity and coherence. For example, Oskar can tell about how he recognized his grandfather, but is unable to recognize why he recognizes him: “To be honest, I don't know what I understood then. I don't think I figured out that he was my grandpa [...] But I must have understood something [...] because why else would I have opened my left hand" (322). Oskar is here mimicking the mute communication of his grandfather, who does not speak, but has a "yes" and a "no" tattooed on the palms of his hands. It is through this physical act of repetition, that Oskar performs without real understanding, that the family history is reestablished. (At the end of the novel, I will argue, the reader also has to inscribe him or herself in the mourning community through the repetition of a physical act.) The same automatic recognition is present in the scene when Thomas Jr (Oskar's father), after a long search, finds his father, Thomas Sr (Oskar's grandfather). In a letter, Thomas Sr explains that at that moment he simply knew that the man in front of him was his son, although he had never seen him before:

'But if he didn't tell you he was your son, how did you know?'

'I knew because he was my son.' (28)

The "norms of recognition" of the other are here established genetically: recognition is possible because it is encoded in an aspect of the subject's being that is both fundamental and out of reach. In these scenes, "family" emerges as the code word for an organic, transhistorical communal tie that is recreated through traumatic experience. Trauma provides the material basis for the thus established affective community because of its status as the liminal, and thus presumably most authentic, bodily experience. The rhetoric of Extremely Loud and Incredibly Close thus echoes the logic by which the body in pain becomes representative (even allegorical) of the nation: through a process of its restoration, healing, or restorative mourning after a traumatic event. This event is foundational, since the community 
reestablished at the site of trauma becomes grounded in the materiality of the ostensibly most unquestionable (because psychically most extreme) bodily experience. The novel thus gives narrative form to the cultural affinity between the notions of organicity of national polity and authenticity of trauma that was politicized and arguably instrumentalized after $9 / 11$. This affinity is often realized, LaCapra reminds us, in the myth of foundational trauma, where trauma unproblematically becomes the basis for communal identity (cf. LaCapra 2001: 3).

The process of authentication of communal ties through a reference to their bodily foundations — or, simply, the community's "anchoring" in the body—is evidenced in the scene in which Oskar digs up his father's coffin because "it's the truth, and Dad loved the truth" (321). The son is looking here for the traumatic, and consequently authentic, core of his subjectivity. The fact that he knows the coffin is empty and finds in it "the dictionary definition of emptiness" (321) supports Brooks' contention that melodrama (a response "to the common concern, in a search for the common ground," 200) "at its most lucid" "recognizes the provisionality of its created centers, the constant threat that its plenitude may be a void . .." (200). But if Foer's melodrama recognizes the fact that the common ground of sociality is ultimately void and open to inscription, it also argues that this void must be filled, or covered up. The inscription of this void basis of both sociality and history that the novel proposes rests on notions of genetic continuity and organic community. Oskar and his grandfather fill the grave with the letters Thomas Sr never sent to his son. That way, Thomas $\mathrm{Sr}$ is symbolically reconnected with his son (by way of the letters), Oskar reunited with his father (by keeping on his hands the dirt, the material trace of his father), and the continuity of the masculine family history is restored. The grave becomes the site of social and historical recuperation: through the ritual of a symbolic encounter with his father, Oskar is ultimately freed from melancholic attachment and is able to re-socialize, while through the equally ritual 
but real encounter with his grandfather, he becomes reconnected to family history. By refusing to wash his hands after the visit to the graveyard, Oskar attempts to stay physically connected to his dead father, hoping that some "microscopic material would be there forever" (323). The novel suggests that successful assimilation into society needs such an an unseen, but present and material, basis of communal ties.

In her Trauma culture, Ann E. Kaplan concludes that "art that takes trauma for its topic but does not allow the spectator so easily to 'survive' the protagonist's death or wound, refuses the safe closure that melodrama perhaps vainly seeks" (125). This remark points to the social work of post-traumatic fiction that, in its melodramatic variant, turns into a fiction of illusory safety ${ }^{5}$. Basically, the melodramatic tone is in line with the novel's socially restorative function. Through Foer's novel, the traumatized national body politic is given an opportunity to work through the traumatic communal experience by way of narrative closure. A look at the melodramatic closure that the novel—Kaplan would argue_- "vainly seeks" can perhaps make it into something more than an illusory search for imagined transcendence, and provide us with an insight into the social mechanisms of communal traumatization and recovery after $9 / 11$.

While the graveyard scene marks the beginning of the anti-social Oskar's transformation into a socialized child, his change is marked in another way: before this turning point, Oskar is obsessed with the photograph of the man falling from the north WTC tower, the same one that first got suppressed, and then revised and reproduced in various forms after $9 / 11^{6}$. Oskar's intention is very simple: he is looking for any clue that would

5 The sense of national safety that Extremely Loud and Incredibly Close nostalgically attempts to re-create should be understood in the context of Susan Lurie's analysis of the social work of the 9/11 "falling man" photographs (cf. Lurie).

6 The photograph of a man falling from the north tower of the WTC on 9/11 was taken by the Associated Press photographer Richard Drew and subsequently circulated through US and international news channels. The desperate act itself, which was in the debate usually referred to as "falling" rather than "jumping," will probably remain the most traumatic moment for the witnesses of the event. In the US, Drew's photograph was published in national newspapers, but only once. After the initial angry reactions from the public, the 
suggest the man in the photograph is his father, and thus-in a move echoing that of the media attempts to identify the falling man — provide him with a sense of closure. He manages to let go of the obsession to recognize his father in the image only after digging up his father's grave and thus, as I argue above, successfully assimilating into his family history. After that, Oskar tears the pages containing the sequence of images of the falling man out of his notebook and reorders them, reversing their chronology. By flipping through the pages, Oskar can get the impression that the man is falling up, towards the tower. This temporal reversal makes him imagine what would have happened if time flew backwards. The novel ends with a sentence that concludes this exercise in nostalgia: "We would have been safe." (326) After that sentence, a sequence of fifteen shots of a person falling from one of the WTC towers follows in reversed order, the same one, we presume, reordered and flipped through by Oskar. The safety Oskar desires thus echoes the general emphasis on national security and safety after 9/11. (Safety is an issue Oskar has to deal with throughout the novel: he wants to take jujitsu self-defense classes, imagines ways of flying out of falling skyscrapers with the help of birds, and avoids the subway, fearing another terrorist attack.) The conditional form Oskar's nostalgia takes starts from the moment when the safety of a communal "we" is destroyed, suggesting that the safety is now, after a period of crisis, reestablished. The final series of images of the falling man summarizes the restorative logic of the novel: time is moving backwards, as the narrative restores societal ties to the imagined, pre-traumatic state of safety. Thus, the novel suggests that social restoration in the face of historical trauma necessarily implies a nostalgic return to an idealized past. In that sense, it appears logical that Oskar's final manipulation of the image, which signals his return to social and psychological

US media decided not to republish the photograph, shunning it to out of public memory. The 9/11: The Falling Man documentary contains interviews with Peter Cheney and Tom Junod, the journalists who tried to identify the man in the photograph. The documentary reconstructs in detail the early public history of the photograph and the attempts to identify the falling man, all of which remain inconclusive. The movie was first shown on BBC Channel 4 on March 16 2006, but apparently not (yet) in the United States. 
normalcy, takes place after a difficult but ultimately successful process of reconciliation with his family, society, and history.

The reader, who automatically repeats Oskar's action by flipping through the last pages of the book, enacts the same restorative/nostalgic ritual of turning back time. Here, Oskar and the reader take the same position and reverse time, restoring safety/normalcy through a manipulation of a media image that has played an important role in the post-9/11 debates about national traumatization, the proper ways of commemorating the tragedy of $9 / 11$, and the role of the media in those processes. As Susan Lurie has argued, the image of falling people effected a nationwide "trauma of spectatorship," that functioned as a cohesive force in the face of the traumatic event (46). The closing sequence of Foer's novel hence connects both Oskar and the reader to the national community that finds its sense of safety through an act of distancing from the traumatic media image. By making the readers repeat this final act of working through, the novel grounds its restorative power literally in the body of its readers, making them participants in the processes of successful national mourning that it enacts, and the resuscitation of community that it narrates. Moreover, in making the readers revisit the site/sight of trauma, Extremely Loud and Incredibly Close points to the crucial role of the media images in the process of both vicarious traumatization (Oskar cannot stop looking for a sign of his father in the image) and normalization (through the final manipulation of images). The end of the novel fulfills a basic post-9/11 US desire: to return to a presumably innocent age of familiar safety. This effect is anchored in two bodies: an observed (dying) one and an observing (living) one. But the mute closing sequence does not simply thematize this desire: it also dramatizes the conditions of its fulfillment. The novel suggests that the enactment of this desire - the desire for a full subjectivity, for an organic community - is possible only through a manipulation of media images. 
WORKS CITED:

9/11: The Falling Man. Dir. Henry Singer. Writ. Tom Junod. BBC Channel 4. March 16, 2006.

Anderson, Benedict. Imagined Communities: Reflections on the Origin and Spread of Nationalism. London \& New York: Verso, 2006.

Barth, John. The Book of Ten Nights and a Night: Eleven Stories. Boston \& New York: Houghton Mifflin, 2005.

Berlant, Lauren. The queen of America goes to Washington city: essays on sex and citizenship. Durham: Duke University Press, 1997.

Brooks, Peter. The Melodramatic Imagination: Balzac, Henry James, Melodrama, and the Mode of Excess. New Haven \& London: Yale UP, 1995.

Butler, Judith. Precarious Life: The Powers of Mourning and Violence. London \& New York: Verso, 2006.

Duara, Prasenjit. "Transnationalism and the Challenge to National Histories," in Bender, Thomas, ed. Rethinking American History in a Global Age. Berkeley \& Los Angeles: University of California Press, 2002: 25-46.

Dudziak, Mary L. September 11 in History: A Watershed Moment? Durham \& London: Duke UP, 2003.

Foer, Jonathan Safran. Extremely Loud and Incredibly Close. Boston \& New York: Houghton Mifflin Company, 2006.

Glass, Julia. The Whole World Over. New York: Pantheon, 2006. 
Hudson, Gabe. "Everything is Interrogated," The Village Voice, March 22, 2005. Accessed April 12, $2006<$ http://www.villagevoice.com/2005-03-22/books/everything-is-interrogated/> Junod, Tom. “The Falling Man,” Esquire. Accessed April $252007<$ http://www.esquire.com/ print-this/ESQ0903-SEP_FALLINGMAN>

Kalfus, Ken. A Disorder Peculiar to the Country. New York: Ecco, 2006.

Kaplan, Ann E. Trauma culture: the politics of terror and loss in media and literature. New Brunswick, N.J.: Rutgers University Press, 2005.

LaCapra, Dominick. Writing history, writing trauma. Baltimore: Johns Hopkins University Press, 2001.

Lurie, Susan. "Falling Persons and National Embodiment: The Reconstruction of Safe Spectatorship in the Photographic Record of 9/11," in Sherman, Daniel J. and Terry Nardin, eds. Terror, Culture, Politics: Rethinking 9/11. Bloomington \& Indianapolis: Indiana UP, 2006: 44-68.

Messud, Claire. The Emperor's Children. New York: Knopf, 2006.

Slaughter, Joseph R. "Enabling Fictions and Novel Subjects: The Bildungsroman and International Human Rights Law," PMLA 121.5: 1405-1423, October 2006.

Solomon, Alisa. "Who Gets to be Human in the Evening News?" PMLA 121.5: 1585-1592, October 2006.

Updike, John. Terrorist. London \& New York: Hamish Hamilton, 2006.

Wasserstein, Wendy. Elements of Style. New York: Knopf, 2006.

White House, The. President Delivers State of the Union Address, January 29, 2002.

Accessed March 23, 2006

<http://www.whitehouse.gov/news/releases/2002/01/20020129-11.html>

---. The National Security Strategy of the United States of America 2002, September 2002. 
Accessed March 23, 2006 <http://www.whitehouse.gov/nsc/nss/2002/nssintro.html> Wiegman, Robyn. "Missiles and Melodrama (Masculinity and the Televisual War)" in Jeffords, Susan and Lauren Rabinovitz, eds. Seeing Through Media: The Persian Gulf War. New Brunswick, NJ: Rutgers UP, 1994: 171-188.

\section{SUMMARY:}

By focusing on Jonathan Safran Foer's Extremely Loud and Incredibly Close, the article analyzes the social work of some popular US novels that incorporate the $9 / 11$ terrorist attacks as a backdrop to family dramas. I argue that the basic narrative logic of these $9 / 11$ fictions corresponds to the hegemonic emplotment of the event, and represents it as a critical moment in which personal, familial, and national history takes a turn towards self-realization. In that, Foer's post-traumatic novel of formation enacts the process of the nation's restorative mourning after $9 / 11$. Inscribed in such a developmental narrative, the trauma of 9/11 becomes a point of suture between the personal and the communal, thus containing the political aspects of the event within the intimate sphere. Moreover, through its use of visual material, the novel points to the crucial role of the media images in the process of vicarious traumatization and societal normalization.

BIO:

Sven Cvek (Pula, 1975) is a doctoral candidate at the Zagreb Faculty of Humanities and Social Sciences. Since 2000 he has been employed by the Faculty's English Department as a teaching assistant at the Chair for American Studies. The article presented here is part of his 
$\mathrm{PhD}$ project on the literary representations of the September 11, 2001 terrorist attacks. 